\title{
Epidemiology and geographical distribution of gastrointestinal parasitic infection in humans in Slovakia
}

\author{
A. DUDLOVÁ1, P. JURIŠ ${ }^{2 *}$, S. JURIŠOVÁ ${ }^{3}$, P. JARČUŠKA² ${ }^{2}$ V. KRČMÉRY, ${ }^{1}$
}

${ }^{1}$ St. Elizabeth University of Health and Social Sciences, Palackého 1, P.O. Box 104, 81000 Bratislava SR; ${ }^{2}$ Faculty of Medicine, Pavol Jozef Šafarik University in Košice, Trieda SNP 1, 04011 Košice, SR, *E-mail: juris.peter777@gmail.com; ${ }^{3}$ National Cancer Institute, Klenova 3019/1, 83310 Bratislava, SR

\section{Article info}

Received June 29, 2016 Accepted September 22, 2016

\begin{abstract}
Summary
Examinations of the set of 2,760 samples of human stools revealed the current epidemiological situation in the occurrence of gastrointestinal parasitoses in Slovakia. Prevalence of gastrointestinal parasitic infection was $P=6.81 \%$ out of which the protozoan infections was $P=2.64 \%$ and helminthiases $P=4.17 \%$, in the representation of endoparasitic species Entamoeba coli, Giardia intestinalis, Blastocystis hominis, Endolimax nana, Ascaris lumbricoides, Trichuris trichiura and Enterobius vermicularis.

The species with the highest proportion from the protozoa was Entamoeba coli $(\mathrm{P}=0.79 \%)$ and from the helminths Ascaris lumbricoides ( $P=3.73 \%)$. The highest prevalence of protozoan infections ( $P$ $=3.27 \%)$ was found in the age group $8-18$ yearly and helminthic infections $(P=5.84 \%)$ in the lowest age group of children at the age of 1 month to 7 years. Almost regularly, there was most frequently infection with Endolimax nana, Giardia intestinalis and Ascaris lumbricoides. By comparison of all age categories, a high statistical significance of differences in the prevalence of helminthiases was found, which most frequently infected children aged from 1 month to 7 years $(X 2, p \leq 0.0001)$. The statistical significance of differences in the incidence of protozoan infections $(X 2, p \leq 0.01)$ and helminthiases $(x 2, p \leq 0.0001)$ was recorded between the compared regions of Slovakia (Western, Central and Eastern Slovakia) with the highest prevalence in the eastern region of Slovakia.

Keywords: current epidemiological situation; prevalence; gastrointestinal parasitoses; helminths; protozoa
\end{abstract}

\section{Introduction}

Endoparasitic infections of gastrointestinal tract in people often run as opportunistic infections, coinciding with other contagious diseases (TB, HIV), and they are a common cause of morbidity as well as mortality of patients and globally belong among the most common infections in the human population.

The occurrence of intestinal parasitic infections is influenced by a lot of factors, such as environmental, socio-economic, labour, health and other (Kumar et al., 2013). The high prevalence of these infections occurs in the poverty stricken areas in the tropic and subtropical regions (Norhayati et al., 2003). Intestinal helminthiases belong among the frequent parasitic infections of people worldwide, especially in developing countries (Desalegn, 2014). Most frequently occurring nematodiases in humans are ascariasis, trichuriasis, enterobiasis, strongyloidiasis, filariasis, and trichinosis. According to the World Health Organization, about 0.807 to $1,221,000,000$ people worldwide are infected with ascariasis, 
604 - 795,000,000 with trichuriasis, and 576 - 740,000,000 with infections caused by hookworms Ancylostoma and Necator (suborder Strongylida) (WHO, 2005).

Globally, more than 1.5 billion people (24 \% of the world's population) are infected with parasitic infections caused by soil-borne helminths, including Ascaris lumbricoides, Trichuris trichiura, helminths of the suborder Strongylida (Necator americanus and Ancylostoma duodenale). Distribution of the occurrence of these infections is widely situated in the tropical and subtropical regions, with the largest number of infected in sub-Saharan Africa, North and South America, China, and East Asia. Immunosuppressed population, combined with the increase in life expectancy, increased migration of population, and tourism development led to rediscovering parasitic infection even in the developed countries. In the Eastern Europe helminthic soil-borne diseases (especially ascariasis, toxocariasis, and trichuriasis), protozoan disease giardiasis and toxoplasmosis remain still endemic. The occurrence of selected food-borne helminthiases including trichinosis, opisthorchiasis, taeniosis, and echinococcosis is frequent, while brucellosis and leptospirosis have an important place in the group of bacterial zoonoses (WHO, 2015).

A fairly good indicator of the population load with endoparasitoses is the data on the contamination of urban waste water in the region observed. Examination of urban waste water and sludge from five monitored wastewater treatment plants (WWTP) in the eastern Slovakia, revealed the total positivity of samples $P=35.87 \%$. In $11.09 \%$ of the samples the 00 (cysts) protozoa, and helminth eggs in $20.87 \%$ were recorded. In the raw municipal wastewater only germs of Giardia spp., Entamoeba spp., eggs of Ascaris spp., and eggs of the strongyloid type were found. In the treated waste water no germs of protozoa or helminths were recorded. The highest presence of germs was in drained stabilised sludge. In all types of sludge from wastewater treatment the 00 (cysts) of protozoa Giardia spp., Cryptosporidium spp., Entamoeba spp., and helminth eggs Ascaris lumbricoides, Trichuris spp., Taenia spp., Hymenolepis spp. and eggs of strongyloid type were also found. In drained stabilised sludge also the eggs of Capillaria spp., Toxocara spp. were detected. From the epidemiological aspect, sewage sludge for its high concentration of oo(cysts) of protozoa, or helminth eggs represent a significant epidemiological risk for the potential spread of endoparasitoses in the environment (Dudlová et al., 2015).

Giardiasis was recorded in Europe in paediatric and adult populations in Albania $(P=11 \%)$ and Turkey $(P=8 \%)$ and in children in
Poland ( $P=1 \%)$. In the southern Europe vector-borne zoonoses including leishmaniasis and Chagas' disease appeared. The risk populations include the Roma population, some groups of immigrants. The main group of helminthic infections in Europe includes soil-transmitted helminthiases as well as alimentary helminthiases and cestodes. Most of these infections occur in the eastern Europe and Turkey. The most common soil-transmitted infections include ascariasis and trichuriasis with prevailing occurrence in children and adults living in the southeastern Europe, Albania (ascariasis $P=1 \%$, trichuriasis $P=12 \%$ ), Armenia (ascariasis $P=4 \%$, trichuriasis $P=1 \%$ ), and in the paediatric population in Poland (ascariasis $P=1-15 \%$, trichuriasis $P<1-8 \%$ ). The highest prevalence of ascariasis $(P=69 \%)$ and trichuriasis $(P=65 \%)$ was published in Turkey in paediatric and adult populations. Enterobiasis incidence was recorded in the eastern Europe (reported in Poland $P=$ $2-40 \%$ in adults and children), Turkey ( $P=5-10 \%$ in children) and it is present in Italy ( $P=13 \%$ in children) (Hotez \& Gurwith, 2011). Slovakia, with its population of $5,423,800.5$ is divided into three areas. The west Slovakia including Bratislava, Trnava, Trenčín and Nitra regions has 2,462,723 residents, the middle Slovakia Žilina, Banská Bystrica regions 1,344,633 inhabitants and the eastern Slovakia Prešov and Košice 1,616,444.5 inhabitants. The Epidemiological Information System (EPIS) of the Public Health Authority in Slovak Republic serving for monitoring of the current epidemiological situation of infectious diseases in the human population in Slovakia does not include official information on the incidence of endoparasitic diseases with exception of toxoplasmosis and taeniosis, and annual maps of regional incidence of helminthiasis and taeniosis (Statistical Office, 2015).

The presented epidemiological study on the prevalence of endoparasitic infections belongs among the largest within the last decade that have been carried out in the territory of Slovakia.

\section{Material and Methods}

In total, the presence of endoparasites was examined in 2,760 people $-1,173$ male and 1,587 female from the three regions of Slovakia (Western, Central and Eastern Slovakia). The set analysed was divided into three age groups, the first group (age 1 month -7 years), the second group (age $8-18$ years), and the third group (age 19 - 88 years). The formalin-ether sedimentation method was used for the examination of stool samples for the presence of protozoan cysts and oocysts (Ritchie, 1948, modi-

Table 1. Prevalence $(P)$ of gastrointestinal parasitoses in the populations from selected regions of Slovakia

\begin{tabular}{lcc}
\hline Parasites & $\mathrm{n} / 2760$ & $\mathbf{P}(\%)$ \\
\hline Protozoa & 73 & 2.64 \\
Helminths & 115 & 4.17 \\
Positive finding & 188 & 6.81 \\
Negative finding & 2572 & 0 \\
\hline $\mathrm{n}$-number of positive samples; $\mathrm{P}$ - prevalence & &
\end{tabular}

$n$ - number of positive samples; $P$ - prevalence 
Table 2. Species representation of endoparasites in positive samples of stool

\begin{tabular}{lcc}
\hline Parasites & $\mathrm{n} / \mathbf{2 7 6 0}$ & $\mathbf{P}(\%)$ \\
\hline Entamoeba coli & 22 & 0.79 \\
Giardia intestinalis & 20 & 0.72 \\
Blastocystis hominis & 18 & 0.65 \\
Endolimax nana & 16 & 0.58 \\
Ascaris lumbricoides & 103 & 3.73 \\
Trichuris trichiura & 22 & 0.79 \\
Enterobius vermicularis & 6 & 0.22 \\
\hline $\mathrm{n}$-number of positive samples; $\mathrm{P}-$ prevalence & &
\end{tabular}

fied). Detection of helminth eggs was carried out by the concentration ovoscopic method using the diagnostic sets Paraprep L- Faecal Parasite Concentrator (Diamondal, France). Subsequently, the samples were examined microscopically. For comparison of age, regions, sex groups and statistical evaluation of the results, the chi-square test $\left(X^{2}\right)$ was used employing the SPSS programme.

\section{Results}

By the examination of 2,760 stool samples in the human population investigated, we found the total prevalence of gastrointestinal parasitoses $P=6.81 \%$. The prevalence of protozoan infections was $P=2.64 \%$, and helminthic infections, $P=4.17 \%$ (Table 1 ). Out of the protozoa the species Entamoeba coli, Giardia intestinalis, Blastocystis hominis, Endolimax nana, and of the helminths Ascaris lumbricoides, Trichuris trichiura, and Enterobius vermicularis were identified (Table 2). Most common species of protozoa was Entamoeba coli $(\mathrm{P}=0.79 \%)$, and of helminth Ascaris lumbricoides $(\mathrm{P}=3.73 \%)$.

In six cases we recorded co-infection with Entamoeba coli and helminthic infection with Ascaris lumbricoides. Infection with Ascaris lumbricoides most commonly occurred with infection with conditionally pathogenic protozoan species Blastocystis hominis as well as with other non-pathogenic protozoa species Endolimax nana and Entamoeba coli, and co-infection with a pathogenic protozoan species Giardia intestinalis was recorded. Infection with Trichuris trichiura occurred simultaneously with infection with Ascaris lumbricoides and protozoan species found (Table 3).

The prevalence of protozoan infections was higher in females $(P=$ $2.90 \%$ ) than that in males $(P=2.30 \%)$, with the highest incidence of Entamoeba coli in both sexes (Table 4 and Graph 1). The prevalence of helminthic infections showed a similar $\%$ in both sexes (males $P=4.94 \%$, and for females $P=3.59 \%$ ). The most frequently identified was the species Ascaris lumbricoides with a higher incidence in males (Table 4 and Fig. 1). The difference in the prevalence of protozoan infections and helminthiases between sexes was not statistically significant.

The highest prevalence of protozoan infections $(P=3.27 \%)$ was found in the age group $8-18$ yearly and helminthic infections $(P=$ $5.84 \%$ ) in the lowest age group of children at the age of 1 month to 7 years. In $8-18$ years old, the most common types of the protozoa were confirmed Endolimax nana, Blastocystis hominis, En-

Table 3. Occurrence of co-infections of endoparasitic species

\begin{tabular}{lcc}
\hline Co-infections & $\mathrm{n} / \mathbf{2 7 6 0}$ & $\mathbf{P}(\%)$ \\
\hline Entamoeba coli, Ascaris lumbricoides & 6 & 0.22 \\
Entamoeba coli, Blastocystis hominis, Ascaris lumbricoides & 1 & 0.04 \\
Endolimax nana, Giardia intestinalis & 1 & 0.04 \\
Endolimax nana, Ascaris lumbricoides & 5 & 0.18 \\
Endolimax nana, Ascaris lumbricoides, Trichuris trichiura & 2 & 0.07 \\
Giardia intestinalis, Entamoeba coli & 1 & 0.04 \\
Giardia intestinalis, Ascaris lumbricoides & 5 & 0.18 \\
Giardia intestilalis, Ascaris lumbricoides, Trichuris trichiura & 2 & 0.07 \\
Blastocystis hominis, Endomimax nana, Ascaris lumbricoides & 1 & 0.04 \\
Blastocystis hominis, Ascaris lumbricoides & 6 & 0.22 \\
Blastocystis hominis, Ascaris lumbricoides, Trichuris trichiura & 1 & 0.04 \\
\hline
\end{tabular}




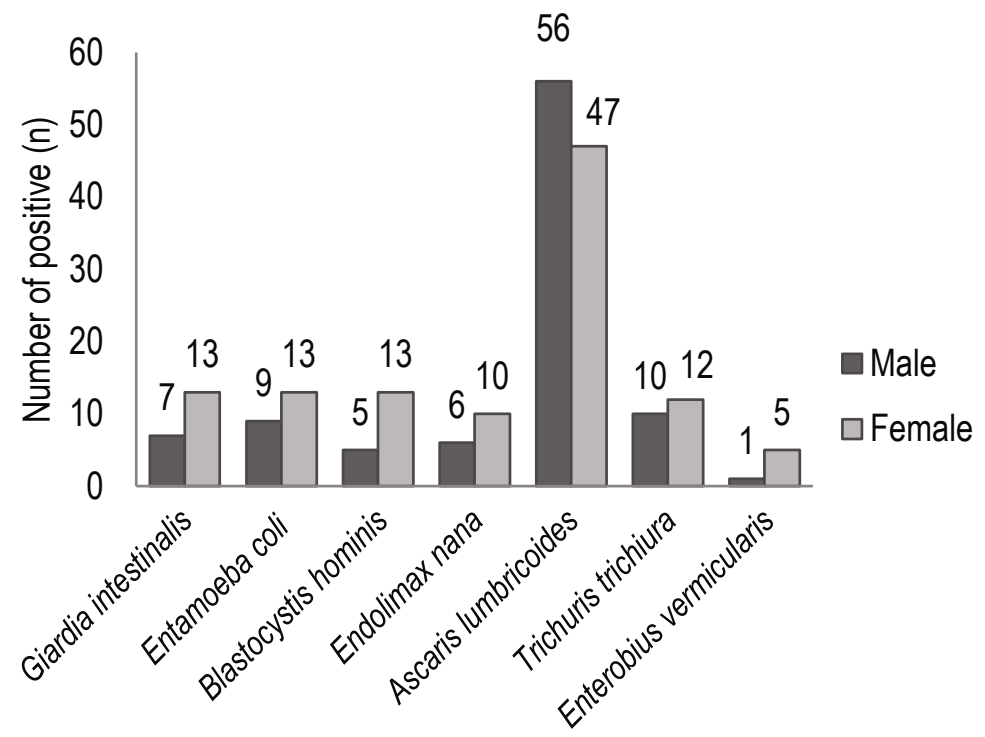

Fig.1. Species representation of endoparasites in dependence on sex

tamoeba coli and out of helminthiases it was Ascaris lumbricoides. Children aged 1 month to 7 years, the most commonly infected with Giardia intestinalis and Ascaris lumbricoides.

The lowest prevalence of protozoan infections ( $P=2.37 \%)$ and helminthiasis ( $P=0.92 \%$ ) was recorded in the age category of 19 - 88 years old, with the most frequently confirmed species Blastocystis hominis and Enterobius vermicularis. The comparison of all age categories revealed a high statistical significance of differences in the prevalence of helminthiases, which were most frequently the cause of infection of children at the age of 1 month to 7 years $\left(X^{2}\right.$, $p \leq 0.0001$ ). The results are shown in Table 4, Fig. 2 and Fig. 3.

The highest positivity for the presence of gastrointestinal parasite germs was found in the population living in the eastern Slovakia $(n=179 / N=2760)$ (Fig. 4). According to number of samples examined, we can compare the real locations in eastern and western
Slovakia, but the results from Central Slovakia is rather an indicative, due to the low number of samples examined. The statistical significance of differences was found in the incidence protozoan infections $\left(X^{2}, p \leq 0.01\right)$ and also helminthiases $\left(X^{2}, p \leq 0.0001\right)$ between the compared regions of Slovakia.

\section{Discussion}

Endoparasitic infections of gastrointestinal tract have a worldwide distribution. The most frequent outbreaks of protozoan infections are associated with the infections with Giardia intestinalis and Cryptosporidium parvum (40.6\% and $50.8 \%$, respectively), next with Entamoeba histolytica and Cyclospora cayetanensis $(1-3 \%)$, and less often the focuses of Isospora belli $(\leq 1 \%)$.

$G$. intestinalis is the most commonly isolated intestinal parasite Table 4. Prevalence $(P)$ of gastrointestinal parasitoses according to sex, age categories and region

\begin{tabular}{|c|c|c|c|c|c|c|}
\hline \multirow[b]{2}{*}{ Sex } & \multicolumn{3}{|c|}{ Protozoa } & \multicolumn{3}{|c|}{ Helminths } \\
\hline & $\mathrm{n} / 2760$ & $P(\%)$ & $x^{2}$ & $\mathrm{n} / 2760$ & $P(\%)$ & $x^{2}$ \\
\hline Male (N=1173) & 27 & 2.30 & & 58 & 4.94 & \\
\hline Female $(\mathrm{N}=1587)$ & 46 & 2.90 & $p=0.33408$ & 57 & 3.59 & $p=0.07872$ \\
\hline \multicolumn{7}{|l|}{ Age } \\
\hline $1 \mathrm{~m}-7$ years $(\mathrm{N}=1267)$ & 31 & 2.45 & \multirow{3}{*}{$p=0.46157$} & 74 & 5.84 & \multirow{3}{*}{$p \leq 0.0001^{* * *}$} \\
\hline $8-18$ years $(N=733)$ & 24 & 3.27 & & 34 & 4.64 & \\
\hline $19-88$ years $(\mathrm{N}=760)$ & 18 & 2.37 & & 7 & 0.92 & \\
\hline \multicolumn{7}{|l|}{ Region } \\
\hline Western Slovakia (N=529) & 5 & 0.95 & \multirow{3}{*}{$p=0.01760^{* *}$} & 3 & 0.57 & \multirow{3}{*}{$p \leq 0.0001^{* * *}$} \\
\hline Central Slovakia (N=70) & 1 & 1.43 & & 0 & - & \\
\hline Eastern Slovakia (N=2161) & 67 & 3.10 & & 112 & 5.18 & \\
\hline
\end{tabular}




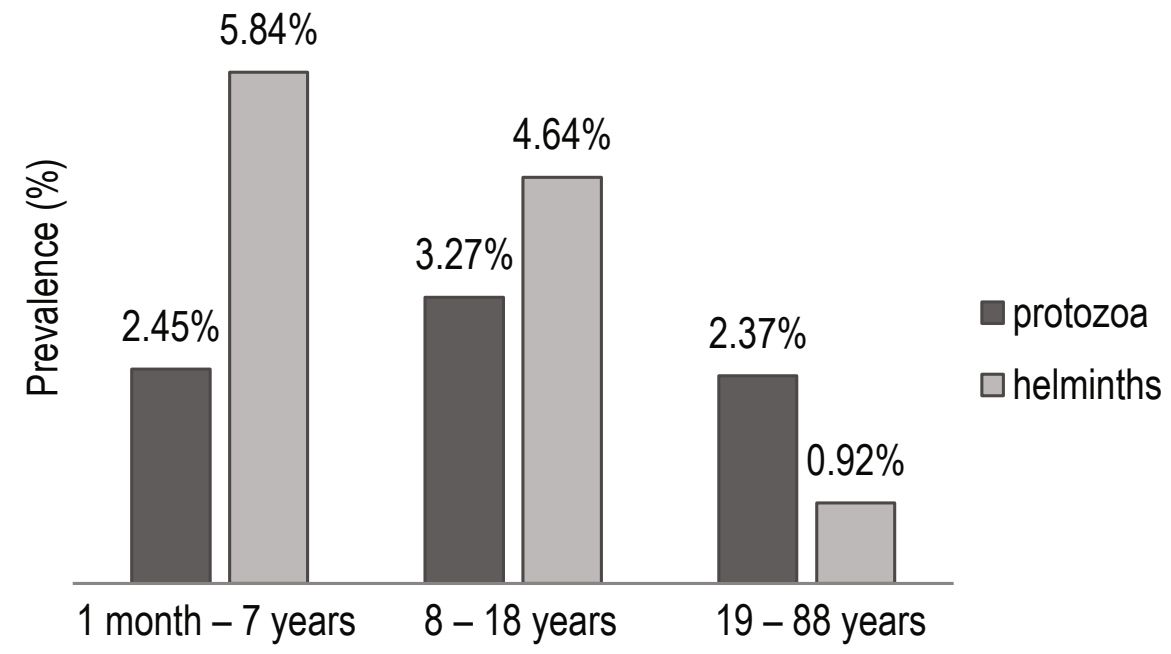

Fig. 2. Prevalence $P(\%)$ of gastrointestinal parasites (protozoa, helminths) in dependence on age

worldwide. The incidence of $20-40 \%$ is referred to the developing countries, particularly in the paediatric population (Vandenberg et al., 2006). In developed countries, the incidence of giardiasis is stated from 2 - 5 \% (Alum et al., 2010). In European countries, giardiasis has the most frequent occurrence, especially in the Eastern Europe and in Turkey (Pappas et al., 2009).

In the human population examined by us the prevalence of protozoan infections $P=2.64 \%$ was found, with the highest prevalence of Entamoeba coli $(\mathrm{P}=0.79 \%)$, which is non-pathogenic species, and the species $G$. intestinalis ( $P=0.72 \%$ ). The highest positivity for the presence of $G$. intestinalis showed the youngest age category (age from 1 month to 7 years). Giardiasis more often affects infants, young children and adolescents than adults (Huston, 2006; Fletcher et al., 2014). The rapid spread of infection can take place in centres for children 12 - 16 months old, or collectives (Guandalini, 2004). Protozoa Entamoeba coli, E. hartmanni, E. polecki, Endolimax nana, and lodamoeba buetschlii are generally considered as non-pathogenic, although they were identified in the stools of patients with diarrhoea, and none of known pathogenic species were found in them. Entamoeba coli infection alone does not cause clinical signs, however, infected individuals can be co-infected with other pathogenic organisms that cause disease. Endolimax nana is a genus of amoebae that was considered nonpathogenic, but some studies suggest that they may cause intermittent or chronic diarrhoea (Issa, 2014). In our population studied, we found the prevalence of $E$. nana $P=0.58 \%$. In developed countries the conditionally pathogenic species of protozoa Blastocystis hominis is often diagnosed. Its role in inducing gastroin-
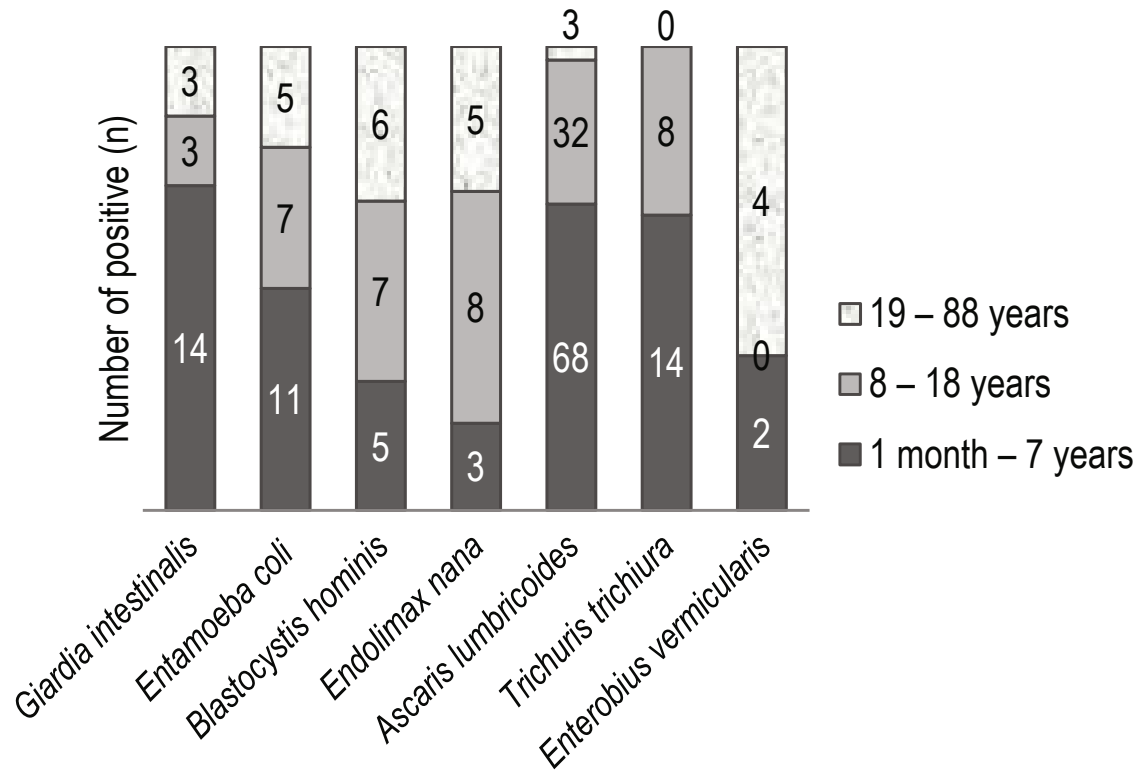

Fig. 3. Species representation of endoparasites in different age categories 


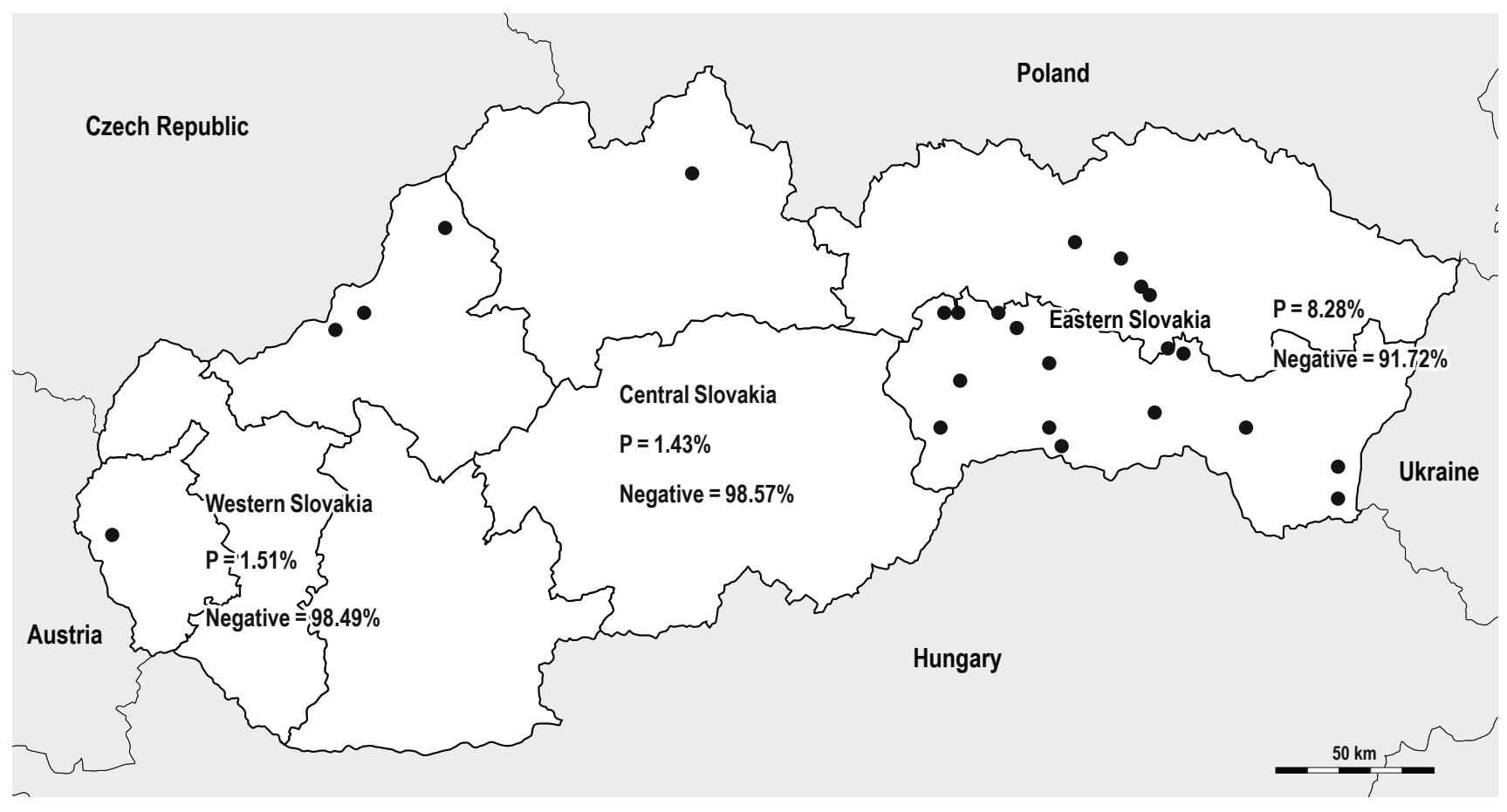

Fig. 4. Geographic distribution of gastrointestinal parasitoses in Slovakia

- Localities with the occurrence of endoparasitoses

testinal symptoms remains uncertain. Clinical symptoms that were attributed to Blastocystis spp. include nausea, loss of appetite, abdominal pain, flatulence, acute or chronic diarrhoea, often associated with chronic gastrointestinal disease of unknown etiology, and irritable intestine syndrome (Fletcher et al., 2014). Distribution of $B$. hominis is global. Prevalence of $54 \%$ and $33 \%$ were recorded in Papua New Guinea and Nepal. In children, the prevalence rate varies from $2 \%$ in Kuwait to $65 \%$ in Papua New Guinea. Studies conducted in Africa have shown that $B$. hominis can be a major cause of diarrhoea in terms of inadequate hygiene (Graczyk et al., 2005). As well, our results of stool examination showed the presence of cysts of $B$. hominis, where the prevalence of $P=0.65$ $\%$ was recorded mainly at the age of 8 years and older. Protozoan infections often occur as co-infections of intestinal bacterial, and other parasitic infections equally as opportunistic infections in a variety of infectious and non-infectious diseases (Fletcher et al., 2014). Infection caused by cryptosporidia, cyclospores, and microsporidia are often detected in the individuals with immunodeficient conditions, e.g. in subjects with HIV infection, after organ transplantation, suffering from other concomitant infections, chronic diseases, oncologic diseases (Kashyap et al., 2010). Protozoa that most commonly cause disease in the individuals with compromised immune systems are Toxoplasma gondii, Trypanosoma cruzi, Leishmania spp., Cryptosporidium parvum, Giardia intestinalis, Isospora belli, Cyclospora cayetanensis, mikrosporidia, less frequently Babesia spp., Entamoeba histolytica, Trichomonas vaginalis, and Balantidium coli (Ferreira, 2000).
The stool examination in this study revealed the prevalence of helminthic infections $P=4.17 \%$. The identified species were Ascaris lumbricoides, Trichuris trichiura, and Enterobius vermicularis with the highest prevalence of Ascaris lumbricoides ( $P=3.73 \%$ ). Ascariasis, the helminthic diseases in humans caused by Ascaris lumbricoides, with an estimated global prevalence in 1 billion people with the highest prevalence in tropical countries reached the character of global disease (Dori et al., 2011). The highest rate of infection incidence with Ascaris is in China, Southeast Asia, the coastal areas of West and Central Africa (Alum et al., 2010).

The incidence of infection with $A$. lumbricoides in co-infection with the protozoa Entamoeba coli, Endolimax nana, Blastocystis hominis, Giardia intestinalis, and T. trichiura helminths was recorded. The higher prevalence of $A$. lumbricoides was recorded in men, but the gender difference was not statistically significant. A. Iumbricoides infection was detected more frequently in younger age categories, namely in children from month 6 to 18 years old. Most positive samples for the presence of $A$. lumbricoides eggs were recorded in one year old children ( $n=18 / 103$ positive), where connection with unsanitary living conditions, socio-economic factors, still unformed hygienic habits, and the incomplete development of the immune system in young children is assumed.

Slight infection runs often asymptomatically, while serious infections tend to lead to acute abdominal pain and ileus from the small bowel mechanical obstruction, especially in children (Bundy \& Brooker, 2014). In endemic countries, intestinal ascariasis is also a common cause of the diseases of liver, biliary tract, and pancreas, 
including possible acute pancreatitis and cholecystitis that result from larval migration through tissues. Abdominal ultrasonography, tomography, and magnetic resonance imaging can identify the cause of the difficulties (Das, 2014). In endemic countries, ascariasis is a common cause of malabsorption syndrome, malnutrition, and lack of trace elements can lead to the failure of growth, cognitive disorders as well as to the defective immune regulations and increased risk of other infections (Lamberton and Jourdan, 2015). The prevalence of ascariasis is directly proportional to the density of population in the region, the level of education, health protection measures with regard to wastewater management, droppings as fertilizer use, personal hygiene, available health care, socio-economic status of the country (Das, 2014). Mortality due to the diseases caused by soil-borne helminths, including ascariasis, trichuriasis is most reported due to severe infections with $A$. lumbricoides with the symptoms of intestinal obstruction, gallbladder and pancreatic diseases in children younger than 10 years (De Silva et al., 1997) .

Within the developmental cycle of $A$. lumbricoides the larvae may also migrate to the lung parenchyma (entero-hepato-pulmonary migration). The immune system mediated hypersensitivity and reactions to migration of larval helminths (Ascaris lumbricoides, Toxocara sp.) through the lung tissue lead to the onset of Loffler's syndrome, or eosinophilic pneumonia. Serological testing points to eosinophilia in the blood and the chest X-ray shows visible pulmonary eosinophilic infiltrates. Serological testing can help to determine the diagnosis, especially when secretion of helminth eggs by faeces (negative testing of stool) did not occur yet, although the cross-reactivity with other parasitic infections is common (Şentürk et al., 2012, Juriš et al., 2014).

Of the helminthic infections our evaluation revealed the presence of eggs of Trichuris trichiura ( $P=0.79 \%$ ) and to the least extent Enterobius vermicularis eggs ( $P=0.22 \%)$, at which the specific tests of paraanal agglutination are supposed. T. trichiura infection usually occurred simultaneously with the infection with $A$. lumbricoides, in some cases also with protozoan infections. The youngest children (2 - 7 years) most often suffered from trichuriasis, and enterobiosis was recorded most frequently in the individuals at the age of 38 55 years. Trichuriasis belongs among the most common helminthic infections worldwide (about 800 million infected individuals), with the highest incidence in warm and humid areas (Dori et al., 2011). The highest prevalence rate was recorded in Central Africa, southern India, and Southeast Asia (Alum et al., 2010).

Enterobiosis is equally widespread global disease, especially in the countries in temperate zones. The most commonly infected are children. The estimated prevalence in the paediatric population in the various regions of the world is from 4 to $28 \%$ (Dori et al., 2011). Helminthic infections occur as opportunistic infections at other ongoing infections. One of them is tuberculosis, which is becoming a major public health risks due to the threat of public health regarding deteriorative socio-economic situation, and the increasing incidence of HIV infection and AIDS. The efficacy of vaccination at reduction of the load of these diseases shows a tremendous variability. Most areas with a high incidence of tuberculosis and poor efficacy of the vaccine against tuberculosis is characterised in a high prevalence of intestinal parasitic infections. These infections cause a number of immunomodulation characterised by the increased Th2 cytokine production, high levels of lgE, and chronic immune activation. The altered immune profile could have a negative impact on the outcome of subsequent infections and vaccinations. In support of this hypothesis, studies in animals and people living in endemic areas of helminthiasis incidence have been conducted, which showed that helminthic infections disrupt the resistance of the organism against a number of infections, including tuberculosis, malaria and HIV. Understanding of these interactions could help in the design of vaccines against some of these diseases (Elias et al., 2007). Co-infection with HIV and intestinal parasite may enhance their virulence (Hosseinipour et al., 2007).

By the comparison of the three regions of Slovakia (western, middle and eastern Slovakia), we found that the prevalence of endoparasitoses was significantly higher in the eastern Slovakia, despite the imbalance in the number of examined samples. Transmission and dissemination of the endoparasitoses is the result of poor hygiene and lack of water infrastructure. The rural communities are particularly endangered whose water resources are extracted from surface water that may be contaminated also with germs of endoparasites. The periods of heavy rain may be particularly important in terms of contamination of water resources by faeces due to lacking of sewerage system of households. Parasitic infections ongoing also in chronic form, weakening the organism as well as related bacterial, fungal, and viral infections affect hundreds of millions of people living in low- and middle-income countries. In Europe, these diseases occur especially in the eastern and southern Europe and in Turkey, where the standard of living and economic level is the lowest (Hotez and Gurwith, 2011). Up to 165 million people in Europe (more than $20 \%$ of the population) live below the poverty line and about $2 \%$ of the European population lives in absolute poverty. This has a significant impact on the incidence and prevalence of parasitic diseases. It is especially a case of the countries located in the southeastern Europe, including the Balkan nations, Albania, Bosnia and Herzegovina, Bulgaria, Croatia, Kosovo, Macedonia, Montenegro, Serbia, Romania as well as Turkey that in Europe are considered to be the poorest nations. The second group of nations characterised by extreme poverty includes some of the former Soviet bloc countries in Europe, i.e Belarus, Azerbaijan, Ukraine, Georgia and Moldova (Stuckler et al., 2009).

In Europe some populations require attention because of their susceptibility to high rates of infection. One of them is the Roma population in which it is estimated that $7-9,000,000$ Roma currently live in the central and eastern Europe, with the largest number in Romania, Bulgaria, then in Macedonia and Slovakia, where they represent over $8 \%$ of the population. $70 \%$ to $80 \%$ of Roma in Bulgaria and Romania live in poverty, where they survive in condi- 
tions of non-standard housing, poor hygiene and suffer from malnutrition. Their exposure to intestinal parasitic diseases, bacterial and viral diseases is very high. The high incidence of giardiasis, shigellosis, salmonellosis and hepatitis, as well as respiratory and ectoparasitic diseases, in particular of pediculosis was recorded (Rechel et al., 2009).

Similar situation is in Slovakia, there are over 1,000 Roma Settlements. Around 150,000 Roma live in segregated places which are unfit for living. Particularly access to safe drinking water have a negative impact on the incidence of infectious diseases (Rimárová, 2010). In Europe the next population at risk is immigrant populations, including migrants from Africa, in which to a high degree occur so-called "neglected infections ", as well as orphans intended for international adoption (Norman et al., 2010).

Stool examination of hospitalised paediatric patients with respiratory diseases in Slovakia (recurrent and chronic bronchitis, bronchial asthma, contact TBC, active TBC, rhinopharyngitis, bronchitis, pneumonitis, cystic fibrosis, fluidothorax, pleuropneumonia) revealed overall prevalence endoparasitoses $P=19.85 \%$; the prevalence of helminthic infections was $P=7.35 \%$. There were represented Ascaris lumbricoides, Trichuris trichiura, Hymenolepis sp., Enterobius vermicularis. The total prevalence of infections caused by protozoa was $P=12.50 \%$ in the following representation: Cryptosporidium spp., Entamoeba spp., Isospora sp., Giardia intestinalis. Out of the helminths the largest representation was in Ascaris lumbricoides, and of protozoa Cryptosporidium sp. The highest prevalence of protozoan infections was in children of the age category 11 - 16 years of age, and helminthic infections in children of the age category $0-5$ years (Juriš et al., 2014).

Similarly, in cancer patients has been recorded incidence of opportunistic endoparasitic infections. The National Cancer Institute in Bratislava, for the last ten years recorded a continuous increase in cancer both in pediatric and adult population in Slovakia. From the above, it is important to monitor the interaction between the primary disease (e.g. respiratory, infectious, oncologic) and endoparasitoses (protozoan infections and helminthoses) which attack the immune system (Communication from Jurišová, 2016 and National Cancer Registry of the Slovak Republic, 2016).

\section{Conclusion}

Examinations of 2,760 faecal samples revealed the current epidemiological situation in the incidence of gastrointestinal parasitoses in the population in Slovakia. The total prevalence of gastrointestinal parasitoses $P=6.81 \%$ was found, the prevalence of protozoan infections was $P=2.64 \%$, and helminthic infections $P$ $=4.17 \%$. To reduce the risk of endoparasitosis spreading in the human population it is necessary to improve the personal hygiene, including environmental hygiene, sanitation, proper disposal and manipulation with urban waste water. Epidemiologically important is the protection of drinking water sources, health education and health care. This must also include proper diagnosis and subse- quent effective therapy of endoparasitic infections in order to reduce the load (contamination) of the environment with the germs of these diseases, and prevent their transmission and spreading especially in the risk economically and socially underdeveloped regions, particularly of the eastern Slovakia.

\section{Acknowledgements}

This study was supported and co-funded from the grant projects Slovak Grant Agency VEGA (contract No. 1/0941/16, 2016-2018).

\section{References}

Alum, A., Rubino, J.R., IJAZ, M.K. (2010): The global war against intestinal parasites-should we use a holistic approach? Int. J. Infect. Dis., 14(9): e732 - e738. DOI: 10.1016/j.jijid.2009.11.036

Brooker, S.J., Bundy, D.A., P. (2014): Soil-transmitted Helminths (Geohelminths). In Farrar, J., Hotez, P.J., Junghanss, T., Kang, G., Lalloo, D.G., White, N.J. (Eds) Manson's Tropical Diseases. 23rded: Elsevier Saunders: 766 - 776

DAs, A.K. (2014): Hepatic and biliary ascariasis. J. Glob. Infect. Dis., 6: 65 - 72. DOI: 10.4103/0974-777X.132042

Desalegn, A. (2014). Health impact of intestinal helminth infections among podoconiosis patients. Trends Bacteriol.: 1 - 6. DOI: 10.7243/2057-4711-1-2

De Silva, N.R., Chan, M.S., Bundy, D.A. (1997): Morbidity and mortality due to ascariasis: re-estimation and sensitivity analysis of global numbers at risk. Trop. Med. Int. Health, 2: $519-528$

Dori, G.U., Tullu, K.D., Alı, I., HiRko, A., MekuriA, G. (2011): Prevalence of hookworm infection and its association with anemia among patients visiting Fenan Medical Center, East Wollega Zone, Ethiopia. Ethiop. Med. J., 49(3): 265 - 271

Dudlová, A., Juriš, P., JarčušKa, P., Čisláková, L., Papajová, I., KRČMÉRY, V. (2015): Epidemiological risks of endoparasitoses spread by municipal waste water. Helminthologia, 52(3): 188 194. DOI: $10.1515 /$ helmin-2015-0032

Elias, D., Britton, S., Kassu, A., Akuffo, H. (2007): Chronic helminth infections may negatively influence immunity against tuberculosis and other diseases of public health importance. Expert Rev. Anti. Infect. Ther., 5(3): 475-484. DOI: 10.1586/14787210.5.3.475 FERREIRA, M.S. (2000): Infections by Protozoa in Immunocompromised Hosts. Mem. Inst. Oswaldo Cruz, 95(1): 159 - 162. DOI: 10.1590/S0074-02762000000700026

Fletcher, S., Caprarelli, G., Merif, J., Andresen, D., Van Hal, S., StARK, D., ElLIS, J. (2014): Epidemiology and Geographical Distribution of Enteric Protozoan Infections in Sydney, Australia. J. Public Health Res., 3(2): 28. DOI: 10.4081/jphr.2014.298

Graczyk, T.K., Shiff, C.K., Tamang, L., Munsaka, F., Beitin, A.M., Moss, W.J. (2005): The association of Blastocystis hominis and Endolimax nana with diarrheal stools in Zambian school-age children. Parasitol. Res., 98(1): 38 - 43. DOI: 10.1007/s00436-005-0003-0 GuANDALINI, S. (2004): Textbook of pediatric gastroenterology and nutrition. United Kingdom: Taylor \& Francis: 804. 
Hosseinipour, M.C., Napravnik, S., Joaki, G., Gama, S., Mbeye, N., Banda, B., Martinson, F., Hoffman, I., Cohen, M.S. (2007): HIV and Parasitic Infection and the Effect of Treatment among Adult Outpatients in Malawi. J. Infect. Dis., 195(9): 1278 - 1282. DOI: 10.1086/513274

Hotez, P.J., GuRWITH, M. (2011): Europe's neglected infections of poverty. Int. J. Infecti. Dis., 15(9): e611 - e619. DOI: 10.1016/j. ijid.2011.05.006

Huston, C.D. (2006): Intestinal Protozoa. In: Feldman, M., FriedMAN, L.S., BRANDT, L.J. (Eds) Sleisenger \& Fordtran's Gastrointestinal and Liver Disease. 8th ed. Philadelphia, PA: Saunders, An imprint of Elsevier Inc, 2: 2420 - 2423 / 106

ISSA, R. (2014): Non-pathogenic protozoa (Review article). Int. J. Pharm. Pharm. Sci., 6(3): $30-40$

Juriš, P., Dudlová, A., FÁbry, J., Melter, J., MišKovská, M., DudÁšKovÁ, E., JarČušKa, P., KRČméry, V., ČIsláková, L., PapajovÁ, I., Sysel, D. (2014): Endoparasitoses in hospitalised paediatric patients with pulmonary disease. Helminthologia, 51(2): 98 - 102. DOI: 10.2478/s11687-014-0216-9

Kashyap, B., Sinha, S., Das, S., Rustagl, N., Jhamb, R. (2010): Efficiency of diagnostic methods for correlation between prevalence of enteric protozoan parasites and HIVIAIDS status - an experience of a tertiary care hospital in East Delhi. J. Parasit. Dis., 34(2): 63 - 67. DOI: 10.1007/s12639-011-0020-0

Lamberton, P.H.L., Jourdan, P.M. (2015): Human Ascariasis: Diagnostics Update. Curr. Trop. Med. Rep., 2(4): 189 - 200. DOI: 10.1007/s40475-015-0064-9

National Cancer Registry of the Slovak Republic (2016): Cancer incidence in the Slovak Republic 2006 - 2009. Retrieved from http://www.nczisk.sk/Publikacie/Pages/Edicia-analytickych-publikacii.aspx

Norman, F.F., Pérez De Ayala, A., Pérez-Molina, J.A., Monge-MailLo, B., Zamarrón, P., López-VÉlez, R. (2010): Neglected tropical diseases outside the tropics. PLoS Negl. Trop. Dis., 4: e762. DOI: 10.1371/journal.pntd.0000762
Pappas, G., Roussos, N., Falagas, M., E. (2009): Toxoplasmosis snapshots: global status of Toxoplasma gondii seroprevalence and implications for pregnancy and congenital toxoplasmosis. Int. J. Parasitol., 39: 1385 - 1394. DOI: 10.1016/j.jpara.2009.04.003

Kumar, P., Rajesh, P., Sneh, L. (2013): An epidemiological profile of human gastrointestinal parasites in Meerut District. Bull. Env. Pharmacol. Life Sci., 3(1): 228 - 231

Rechel, B., Blackburn, C.M., Spencer, N.J., Rechel, B. (2009): Access to health care for Roma children in Central and eastern Europe: findings from a qualitative study in Bulgaria. Int. J. Equity Health, 8: 24. DOI: 10.1186/1475-9276-8-24

RImÁrovÁ, K. (2010): The Health of the Roma People in Central and Eastern Europe. Košice, Equilibria: 28 - 29

RITCHIE, L.S. (1948): An ether sedimentation technique for routine stool examinations. Bull. U. S. Army Med. Dep., 8: 326

Şentürk, T., Özdemir, B., Keçebaş, M., Beşli, F., Yesilburssa, D., SERDAR, O.A. (2012): Ascaris - induced eosinophilic myocarditis presenting as acute ST elevation myocardial infarction and cardiogenic shock in a young woman. J. Cardiovasc. Med. (Hagerstown), 13(3): 211 - 215. DOI: 10.2459/JCM.0b013e32833db0ca

Stuckler, D., Basu, S., Suhrcke, M., Coutts, A., Mckee, M. (2009): The public health effect of economic crises and alternative policy responses in Europe: an empirical analysis. Lancet, 374: 315 323. DOI: 10.1016/S0140-6736(09)61124-7

Statistical Office OF the Slovak Republic (2015): Public database data. Stat dat, retrieved from http://statdat.statistics.sk/

Vandenberg, O., Peek, R., Souayah, H., Dediste, A., Buset, M., Scheen, R., Retore, P., Zissis, G., Van Gool, T. (2006): Clinical and microbiological features of dientamoebiasis in patients suspected of suffering from a parasitic gastrointestinal illness: a comparison of Dientamoeba fragilis and Giardia lamblia infections. Int. J. Infect. Dis., 10(3): 255 - 261. DOI: 10.1016/j.jijid.2005.05.011

WHO (2005): Deworming for health and development. Report of the third global meeting of the partners for parasite control. Retrieved from http://www.who.int/mediacentre/factsheets/fs366/en/ 